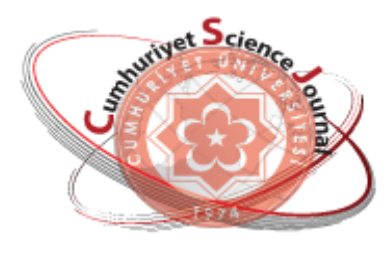

e-ISSN: 2587-246X

ISSN: $2587-2680$

\section{Cumburiyet Seience Journal $\cos$}

Cumhuriyet Sci. J., Vol.40-2 (2019) 347-354

\title{
Dose Calculations of SPECT Simulations on Dynamical Targets with GATE / GEANT4
}

\author{
Sinan KUDAY ${ }^{1}$ \\ ${ }^{1}$ Istanbul Aydin University, Application and Research Center For Advanced Studies, 34295, Istanbul, TURKEY
}

\begin{abstract}
Simulations of SPECT studies have been taken attention with the fact that more accurate results can be constructed in medical imaging with developing computing techniques. As a result, one can visualize new ideas or improvements with the help of medical simulations before applying on real incidents for clinical purposes acquiring high level of statistics without harming live tissues. In this study, we focused on the capability of GATE (a simulation toolkit for PET \& SPECT) that is developed under GEANT4 simulation framework and applications on the effects such as activity degradations, displacements and overlapping of the tissues. Energy histograms and dose calculations are obtained by using built-in tissues and analyzing virtual data using ROOT analysis software. Results show the magnitudes of effects that may have a significant disturbance on SPECT images and their dependence on spesific parameters.
\end{abstract}

Keywords: SPECT, CT, Geant4, GATE, ROOT, Simulation.

\section{GATE / GEANT4 ile Dinamik Kaynaklar üzerinde SPECT Benzetimlerinin Doz Hesaplamaları}

\begin{abstract}
Özet. SPECT çalışmalarının simülasyonları, gelişen bilgisayar teknikleriyle birlikte tıbbi görüntülemede daha doğru sonuçların elde edilebileceği gerçeğine dikkat çekmektedir. Sonuç olarak, canlı dokulara zarar vermeden yüksek düzeyde istatistik elde etmek için gerçek olaylara uygulanmadan önce tıbbi simülasyonların yardımıyla yeni fikirler veya iyileştirmeler görselleştirilebilir. Bu çalışmada, GEANT4 simülasyonları çerçevesinde geliştirilmiş GATE (a simulation toolkit for PET \& SPECT) yazılımının yetenekleri ile aktivite azalmaları, yer değiştirmeler ve dokuların üst üste gelmeleri gibi etkilerin uygulamaları üzerine yoğunlaştık. Enerji histogramları ve doz hesaplamaları, öntanımlı dokular kullanılarak ve ROOT analiz yazılımı kullanılarak sanal verilerin analiz edilmesiyle elde edildi. Sonuçlar, SPECT görüntülerde ve bunların spesifik parametrelere bağımlılıklarında önemli bir bozulmaya neden olabilecek etkilerin büyüklüğünü göstermektedir.
\end{abstract}

Anahtar Kelimeler: SPECT, CT, Geant4, GATE, ROOT, Benzetim.

\section{INTRODUCTION}

Single photon emission computed tomography (SPECT), as one of the most effective techniques in nuclear imaging for functional visualization of human or animal bodies [1], is based on the detection and reconstruction of gamma photons that decayed by the radiotracers introduced into the body before the process. A SPECT system contains gamma cameras that is fixed on the gantry and rotates around the target (body) that is of interest recording the two-dimensional projection of a three-dimensional activity distribution of radiotracers [2]. Afterwards, a serial algorithms are executed to reconstruct the three 
dimensional real-like images from acquired twodimensional images by the SPECT system. As a medical imaging technique, SPECT, can be considered together with a CT system that forms the hybrid usage of both technologies named as SPECT / CT. Considering their scan geometries, 5 generations of CT systems may be classified for multi purposes by the time they are firstly introduced in 1960s [3, 4]. Fifth generation CT systems are convenient to make detections with cylindrical scanners and prepare source as a cone beam from higher energy X-ray sources. On the other hand, third and fourth generation CT systems use fan beam scanners with multiple array of detectors in different geometries. Recent hybrid systems are quite succesfull processing and superposing both SPECT and CT images allowing to detect targeted lesions $[5,6]$. Because of their fast scanning features, it is not surprising to see handheld SPECT devices used in combination with a thoracoscopic gamma detector that are already introduced to mark smal sized nodules during surgical excision [7].

In the fundamental principles of SPECT data acquisitions, it needs to be reconstructed 3D/4D models from 2D spectrums of target using a Fourier transform. This process actually corresponds a modelling simulation taking into account the attenuation effects and the measurement errors [8]. Thus one can understand the simulation need in a hybrid procedure as SPECT / CT imaging in two ways: i. modelling from CT image reconstructions, ii. modelling from irradiation of radiotracers injected in the target. Note that since both of the simulation types help oncologists providing different certainities and sensitivities, a hybrid imaging procedure overlaps two models together to obtain a better conclusion: CT reconstruction algorithms are based on grey scale measurements from X-ray frequencies and SPECT algorithms use track distributions of lesions from radiated gamma measurements. Thus one can understand the aim of a SPECT simulation as creating a realistic model to trace development of diseases [9]. In order to complete this task, not only visually but also numericaly realistic model needs to be simulated to obtain quantitative changes in dose volumes and irradiation distributions. In addition to the above mentioned, for educational purposes, simulations of medical techniques seem to be the most accurate and harmless solution.

In this work, we have used a setup based on the SPECT benchmark of GATE v8.1 (a simulation toolkit for PET \& SPECT) running under the GEANT4 framework that is developed as a detector simulation for general purposes at CERN [10]. Thus, one can consider GATE package as a medical physics oriented tool that consists of several applications in imaging, radiotherapy, realistic phantom categories as well as internal dosimetry for preclinical applications. It is worthwhile to mention that GATE is more comphrensive and precise than some of its successors that is also developed uder Geant4 framework [11] while we are noting that all of these softwares are still under development.

For years, CERN as a major experimental laboratory based on the nuclear researhes, also issued studies that has brought high technology and insights in to medical researches. Not only producing isotopes that are needed ingrediants of radiopharmaceuticals in ISOLDE collaboration but also supporting new design ideas of medical accellerators on cancer treatments in university/institute collaborations [12]. Especially after the major upgrade of Geant 4 in 2015 releasing the version 10.0, medical simulations based on Geant 4 frameworks began to be considered as the detailed detector simulations that have the highest resolution in imaging and complex geometries in setup.

The outline of our paper has been prepared as; the definitions of main simulation setup and geometries in section II, considered dynamical cases in data acquisition in section III, analysis and dose calculations in section IV and presenting the results with a brief interpretation in section V.

\section{GATE/GEANT4 SIMULATIONS}

\subsection{GATE/GEANT4 Simulation Setup}

At the first stage of this study, we have followed the procedure preparing a macro to create a SPECT 
geometry as mentioned in GATE user manual [13]. In Fig.1, a simple box geometry that has the dimensions of $7 \times 21 \times 30 \mathrm{~cm}$ is shielded with lead and repeated 4 times to obtain SPECT heads. (Note that some of the SPECT systems already have 3 heads.) SPECT head system is made of three levels: base (white), collimator (red) and crystal (yellow). Base geometry of SPECT heads are placed in a ring orbit with $0.15 \mathrm{deg} / \mathrm{s}$ fixed velocity. A collimator geometry with lead shielding is created in $3 \times 19 \times 28 \mathrm{~cm} \quad(3 \mathrm{~cm}$ thickness) dimensions and hexagone paralell holes are placed around $\mathrm{Y}-\mathrm{Z}$ axis. For the last level, a NaI crystal volume has been created as the main read-out of the system in $1 \mathrm{~cm}$ thickness and placed after collimator layer. A back compartment in $2.5 \mathrm{~cm}$ thickness made of glass is placed as the last layer. For the middle stage; a table surface made of glass, cylindrical phantom and cylindrical source geometries are created with $20 \mathrm{~cm}$ height and 15 $\mathrm{cm}$ radius. Translations and materials for these geometries are chosen from different tissues during the data taking to simulate dynamic effects that will be mentioned in the next sections. For simulated activity, a source confinement is defined in the phantom and a gamma source set at $140 \mathrm{KeV}$ energy with $15 \mathrm{KBq}$ activity by default.

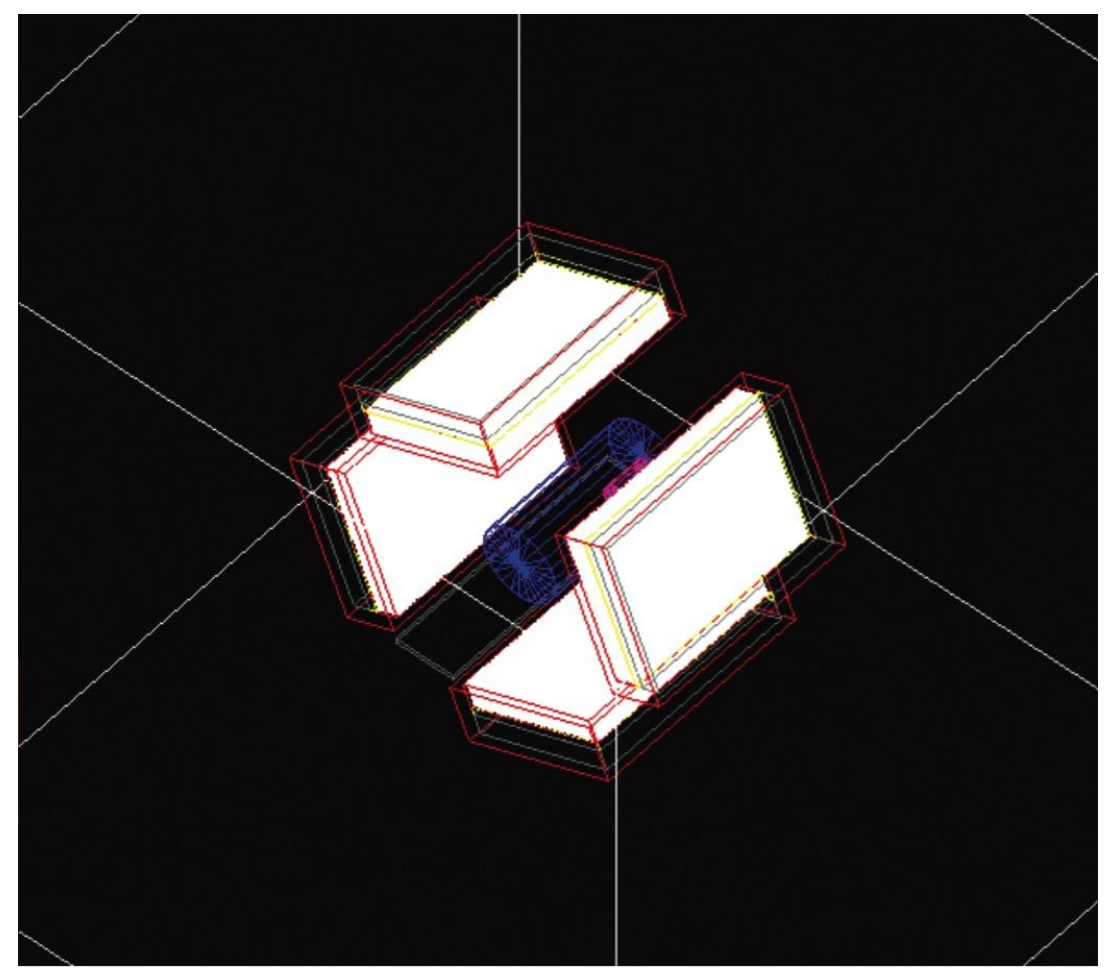

Figure 1: Virtualization of SPECT scene with the placements of base, four NaI cameras, collimators and cylindrical phantom on the table surface.

\subsection{Simulation Specifications}

Dominant physics processes are included as standard model e- interactions, rayleigh \& compton scattering, photoelectric effect, electron ionisation and bremsstrahlung. The simulated data acquired by 5 second intervals from 4 different angles along a circular orbit. Compton events occurring in the phantom, collimator, back compartment, shielding and table are recorded. However, defining a dose actor into propoer regions of the simulation setup can record direct dose values obtained from the source. In order to observe detector outputs from SPECT device, one should modelize data digitization process in a simulation. An output is obtained more realisticly after applying blurring process that will gain resolution and distribution. Gaussian energy blur is applied to the events detected in the crystal, using an energy resolution of $10 \%$ at $140 \mathrm{keV}$. The limited spatial resolution 
of the photomultipliers and associated electronic is modelled using a Gaussian blur with a standard deviation of $2 \mathrm{~mm}$. Thus, one can calculate FWHM of a pulse if it is assumed to has a Gaussian distribution as $\mathrm{E} \times \mathrm{R}$ where $E$ is the peak energy and $R$ is the resolution. Default random number generator is used and seeded differently for each run.

Dose calculations are calculated from the acquired gammas from the located source in the center of the cylindrical phantom. A dose actor element is created attaching to the SPECT head volumes and the root analysis outputs are obtained at the end of each run. As running a previously coded a root macro over outputs, DVH (Dose Volume Histograms) are calculated and plotted as described in section IV. Profile histograms in Fig.2 shows the outputs for the world volume with default activity values in $\mathrm{X}-\mathrm{Y}, \mathrm{X}-\mathrm{Z}$ and $\mathrm{Y}-\mathrm{Z}$ point of views respectively.
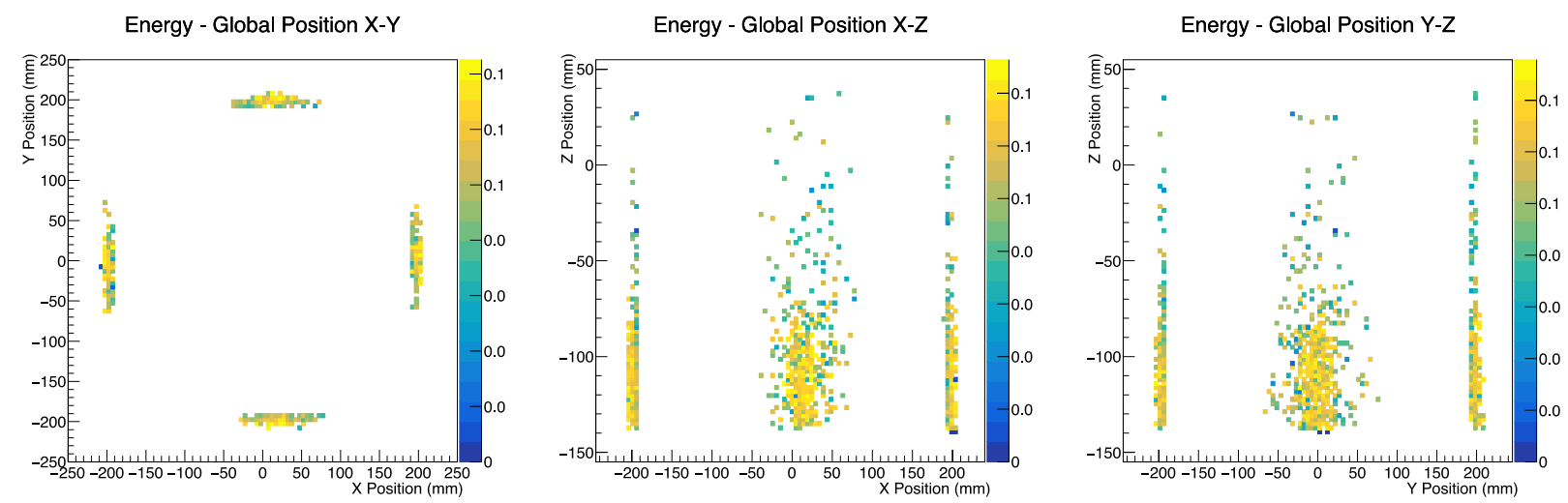

Figure 2: Global distributions based on the world volume for X-Y, X-Z and Y-Z surfaces respectively.

\section{SIMULATED DATA PRODUCTION}

In this work, we considered several dynamical cases for target, namely a cylindirical phantom, that may cause possible failures in SPECT imaging as follows:

1. Activity Degradations: Intravenously or intracavitary injected radiopharmaceutical include high-affinity molecules as carriers to tumor cells. Thus, radiopharmaceutical has two important components: Chemical compound and radionuclide. One of the most common problems in radiopharmaceutical productions is impurity of substances due to the fact that it is not possible to treat molecules one by one in atomic level. Such impurities can not be observed directly but may block bonding of radionuclide molecules to targeted tissues. If this is the case, one can expect activity degradations during medical imaging processes such as SPECT. We simulated activity degradations by reducing gamma activity in data taking from SPECT-head starting from $40000 \mathrm{~Bq}$ with $5000 \mathrm{~Bq}$ intervals. Total activities are acquired similar to Fig. 2 but with less entries after each reduction. We give statistical analysis and related DVHs from our calculation in the next section.

2. Volume Displacements: We refer here natural displacements and movements during radiological imaging such as breathing, heart beating or reflexinduced motions of patient that have the small amplitudes. In order to simulate the motions, one can categorize them according their coordinates and directions: translational and rotational motions. SPECT devices usually apply built-in correction algorithms for correcting rotational movements but not for translational movements. The main reason for that translational movements may be unrepeated movements to predict before the action comparing with the rotational movements. It is possible to create such an algorithm defining a fourier transform from a given reference frame to acquired image. Hence that calculating the transform phase and peak will yield the idea of how much correction is needed in the frame or confidence level. In this work to simulate volume 
displacements, we set translations for the phantom with $0.5,1,1.5$ and $2 \mathrm{~cm}$ respectively. Profile histograms for the source has reflected the direct image of a squeezing phantom as in Fig. 3 for 20 seconds time intervals. For this dynamical case, each run has been merged to form one single continuous run.
Energy - Source Position X-Y

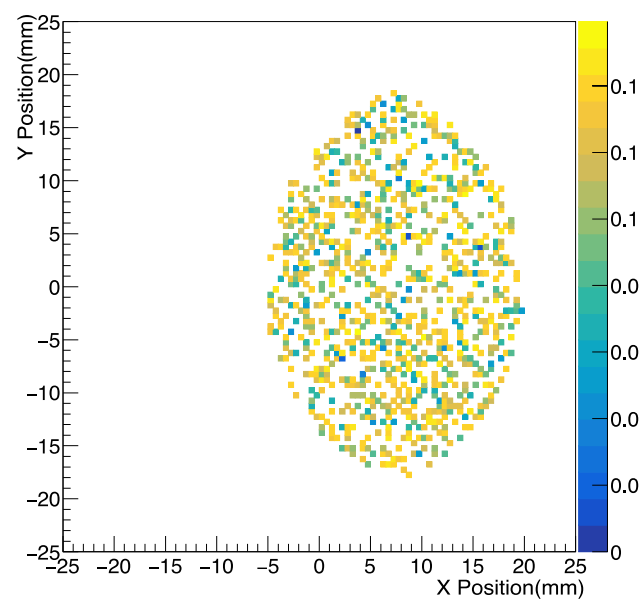

Energy - Source Position X-Y

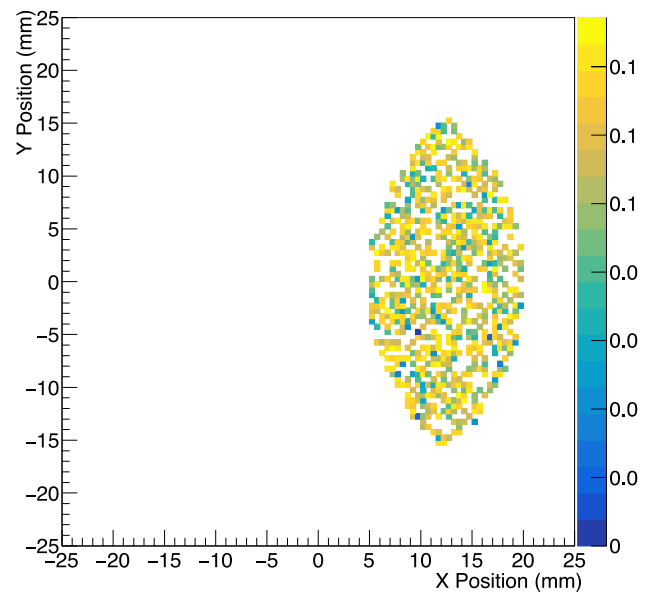

Energy - Source Position X-Y

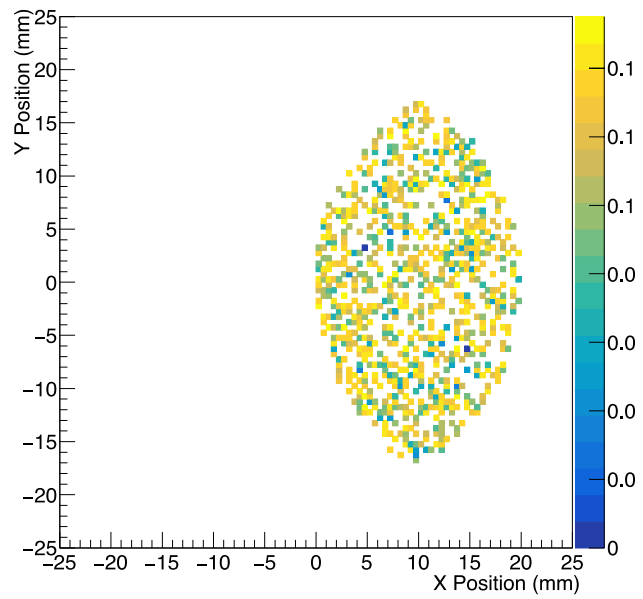

Energy - Source Position X-Y

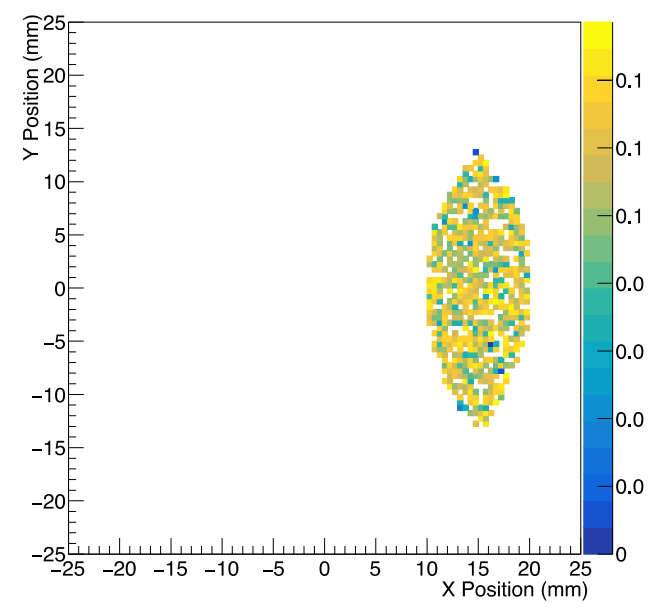

Figure 3: As an example to respirational motion, source profile histograms of small displacements with $0.5,1,1.5$ and $2 \mathrm{~cm}$ respectively on the $\mathrm{X}-\mathrm{Y}$ surface.

3. Tissue / Material Overlapping: A common and inevitable problem in nuclear imaging can be considered as tissue overlapping that refers to intervening of untargeted organs during diagnosis or treatment. Succesively, that problem increases the attenuation probability since the untargeted organs have potential to absorb doses. SPECT / CT system, that applies attenuation correction algorithms removing soft tissue artifacts from medical images, allows a better accuracy. However it is an important knowledge that how much energy will be absorbed by those tissues and in what significances. We have defined several tissues and materials as below (where $d$ is the density and NoA is number of atoms) and placed around the gamma source and calculated the absorbed dose distributions as in the next section. A statistical analysis of the data yields the significances if those distribution differences are at the important levels. Differences from vacuum and 100\% overlapping cases are considered where the source completely covered by the material. 
Air: $\mathrm{d}=1.29 \mathrm{mg} / \mathrm{cm}^{3}$; State = gas; Elements (Fraction) : Nitrogen (0.755268); Oxygen (0.231781); Argon (0.012827); Carbon (0.000124).

Blood: $\mathrm{d}=1.06 \mathrm{~g} / \mathrm{cm}^{3}$; State $=$ liquid; Elements (Fraction) $=$ Hydrogen (0.102); Carbon (0.11); Nitrogen (0.033); Oxygen (0.745); Sodium (0.001); Phosphor (0.001); Sulfur (0.002); Chlorine (0.003); Potassium (0.002); Iron (0.001).

Body: $\mathrm{d}=1.00 \mathrm{~g} / \mathrm{cm}^{3}$; State $=$ solid; Elements $($ Fraction $)=$ Hydrogen $(0.112)$; Oxygen $(0.888)$.

Plastic: $\mathrm{d}=1.18 \mathrm{~g} / \mathrm{cm}^{3}$; State=solid; Elements $($ NoA $)=$ Carbon $(5)$; Hydrogen (8); Oxygen (2).

Water: $\mathrm{d}=1.00 \mathrm{~g} / \mathrm{cm}^{3}$; State=liquid ;Elements $($ NoA $)=$ Hydrogen $(2) ;$ Oxygen $(1)$.

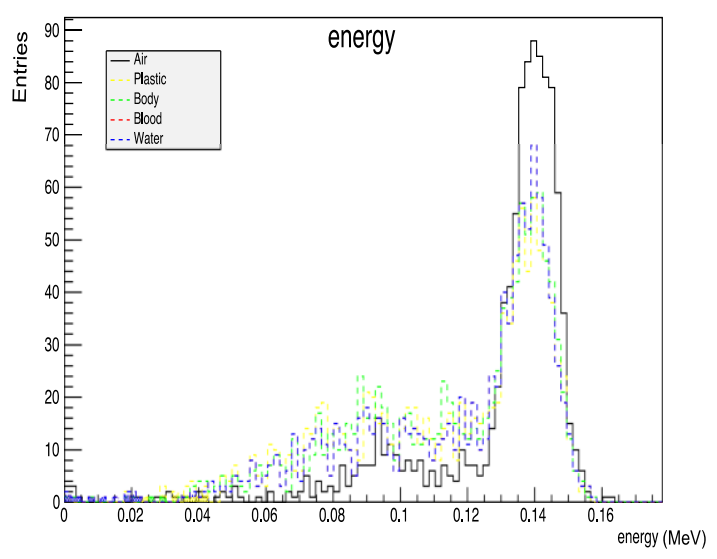

Figure 4: Energy histogram based on the different materials show the overlapping effect on tissues in arbitrary units.

\section{ANALYSIS OF ENERGY \& DOSE CALCULATIONS}

After data is obtained in root file format, a simple macro script is created to calculate absorbed dose percentages in a given volume $V$ as $d\left(D_{0}-D\right) / d V$ where $\mathrm{D}_{0}$ is the dose of the source and $\mathrm{D}$ is the measured dose by the SPECT system. Target volume has been differantiated in a loop and dose values against each volume calculated as in Fig.5, Fig.6, Fig.7. Apparent dose differences are observed except for similarly defined materials such as blood and water in Fig.7. Thus, instead of using built-in materials, one should define materials with more details to conclude dose separations in such plots. However, in order to realize if those values are at important levels, one can implement a $\chi^{2}$ test of indepence as statistical analysis separetely constructing null and alternative hypothesis. One can call null hypothesis as "A single image case (Activity Degradations / Volume Displacements / Tissue Overlapping) has no effect on dose measurements" and its opposite as the alternative hypothesis. Therefore, we calculated the $\chi^{2}$ values as follows where $O$ is the observed values, $E$ is the expected values and $\mathrm{i}$ is the number index for the measurement;

$$
\chi^{2}=\sum_{i}\left(O_{i}-E_{i}\right) / E_{i}
$$

Here we call expected value as $40000 \mathrm{~Bq}$ for activity degredations, $0 \mathrm{~cm}$ for volume displacements and vacuum environment for tissue overlappings. In Table $1, \chi^{2}$ values are revealed for each case to decide accepting the null hypothesis or not. Basicly, a standart $\chi^{2}$ table should be used for relevant significance levels.

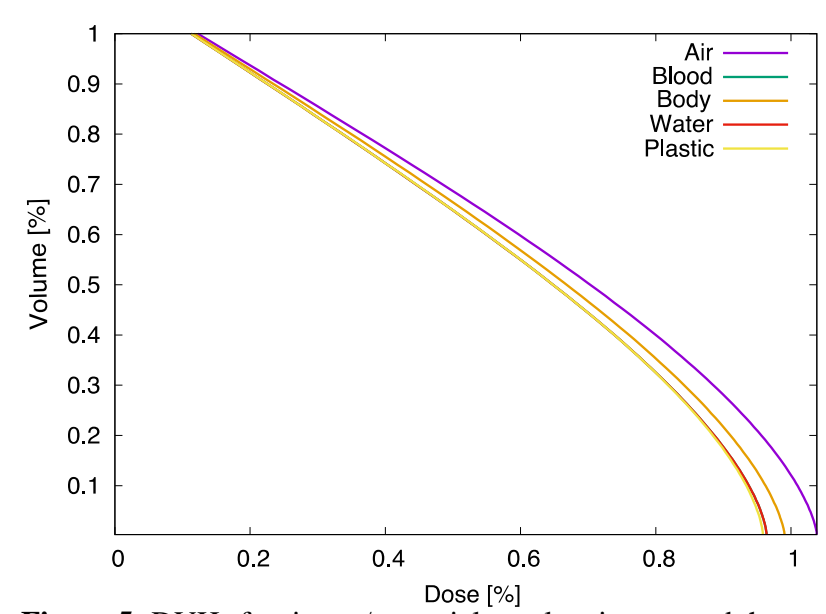

Figure 5: DVHs for tissue / material overlapping around the $40000 \mathrm{~Bq}$ gamma source. 
Table 1. Calculated $\chi^{2}$ values of doses for the considered imaging cases

\begin{tabular}{|c||c|c|c|c|c|c|}
\hline Activity Degradations & $15000 \mathrm{~Bq}$ & $20000 \mathrm{~Bq}$ & $25000 \mathrm{~Bq}$ & $30000 \mathrm{~Bq}$ & $35000 \mathrm{~Bq}$ \\
\hline \hline & 1.48 & 1.023 & 0.77 & 0.3 & 0.073 \\
\hline \hline Volume Displacements & $0.5 \mathrm{~cm}$ & $1 \mathrm{~cm}$ & $1.5 \mathrm{~cm}$ & $2 \mathrm{~cm}$ & $2.5 \mathrm{~cm}$ \\
\hline \hline Tissue / Material Overlapping & Blood & Body & Plastic & Water & Air \\
\hline \hline & & 0.0034 & 0.008 & 0.014 & 0.048 & 0.07 \\
\hline
\end{tabular}

\section{CONCLUSION}

In this letter, we have qualitatively investigated that if one can observe significant disturbances in imaging via the SPECT simulations of GATE / Geant4. Note that for $\alpha=0.9$, volume displacements with more than $2.5 \mathrm{~cm}$, activity degradations with more than $15000 \mathrm{~Bq}$ and tissue / material overlappings with heavier than $1.25 \mathrm{~g} / \mathrm{m}^{3}$ density will significantly effect on dose measurements. Thus, one should have to apply additional correction methods if any of the SPECT runs have suffered from above mentioned issues. According to recent medical publications, those result show that the SPECT calibration of GATE is quite accurate meeting the realistic expectations.

\section{REFERENCES}

[1] Buck K. A., Nekolla S., Ziegler S., Beer A., Krause A. J., Herrmann K., Scheidhauer K., Wester H., Rummeny E. J., Schwaiger M., Drzezga A., SPECT/CT , J. Nucl. Med., 49-8 (2008) 1305-1319.

[2] Bybel B., Brunken R. C., DiFilippo F. P., Neumann D. R., Wu G., Cerqueira M. D., SPECT/CT Imaging: Clinical Utility of an
Emerging Technology, Radiographics, 28-4 (2008) 1097-1113.

[3] Madsen, M.T., Recent advances in SPECT imaging., J Nucl. Med., 48-4 (2007) 661-673.

[4] Groch, M.W., Erwin, W. D., SPECT in the year 2000: Basic Principles, J. Nucl. Med. Technol., 28-4 (2000) 233-244.

[5] Habib, Z., Hasegawa, B., Determination of the Attenuation Map in Emission Tomography, J. Nucl. Med., 44-2 (2003) 291-315.

[6] Khalil M. M., Tremoleda J. L., Tamer B. Bayomy, and W. Gsell, Molecular SPECT Imaging: An Overview, International Journal of Molecular Imaging, 796025 (2011) 1-15

[7] Müller J., Putora P. M., Schneider T., Zeisel C., Brutsche M., Baty F., Markus A., Kick J., Handheld single photon emission computed tomography (handheld SPECT) navigated video-assisted thoracoscopic surgery of computer tomography-guided radioactively marked pulmonary lesions, Interactive CardioVascular and Thoracic Surgery, 23-3 (2016) 345-350.

[8] Patton, J.A., Turkington T.G., SPECT/CT physical principles and attenuation correction., J. Nucl Med Technol., 36-1 (2008) 1-10. 
[9] Keenan, M. A., Stabin M. G., Segars W. P., Fernald M. J., RADAR Realistic Animal Model Series for Dose Assessment, J. Nucl. Med., 51-3 (2010) 471-6.

[10] Jan, S., et. al., GATE - Geant4 Application for Tomographic Emission: a simulation toolkit for PET and SPECT, Phys Med Biol., 49-19 (2004) 4543-4561.

[11] Arce P., Mendes P. R., Lagares J. I., GAMOS: a GEANT4-based Easy and Flexible Framework for Nuclear Geant4 Simulations, IEEE Proc. Nuc. Sci. Symp. Conf. Rec., 1 (2008) 3162 - 3168.

[12] CERN-MEDICIS Collaboration, CERNMEDICIS (Medical Isotopes Collected from ISOLDE): A New Facility, Appl. Sci., 4-2 (2014) 265-281.

[13] http://www.opengatecollaboration.org/sites/d efault/files/GATE-UsersGuideV8.0.pdf 